\title{
Possibilidades e limites da postura colaborativa e investigativa do professor como tática de enfrentamento da complexidade da docência
}

\author{
Eliane Matesco Cristovão* \\ Juliana Facanali Castro*
}

\section{Resumo}

Como pesquisadoras da complexidade da docência e da formação de professores em contextos colaborativos, apresentamos e discutimos alguns desafios enfrentados cotidianamente por professores que ensinam matemática, bem como possíveis táticas (DE CERTEAU, 1994) para seu enfrentamento. Descrevemos alguns desses desafios, permeando referenciais teóricos sobre as temáticas com reflexões provenientes de nossas experiências docentes e de integrantes de grupos colaborativos e investigativos. Apontamos a postura investigativa e o apoio de grupos colaborativos (FIORENTINI, 2004) ou comunidades de investigação/aprendizagem (COCHRAN-SMITH; LYTLE, 1999) como caminhos possíveis para auxiliar os professores no enfrentamento desses desafios. Entretanto, reconhecemos que essas alternativas possuem limitações, principalmente, quando os desafios apresentados aos professores ultrapassam as fronteiras das salas de aula.

Palavras-chave: Colaboração. Limites. Matemática. Postura investigativa. Possibilidades. Professor.

\section{Introdução}

A profissão docente tem se revelado cada vez mais complexa e repleta de desafios. O estudo de tais desafios, bem como das formas pelas quais os professores os têm enfrentado, é parte integrante de nossos trabalhos de pesquisa. Neste artigo, procuraremos colocar em diálogo as observações oriundas desses trabalhos, os referenciais teóricos que embasam sua análise e nossas experiências de professoras de

Doutoranda em Educação Matemática vinculada ao Programa de Pós-Graduação da FE/Unicamp, grupo Prapem. Professora e coordenadora do Curso de Licenciatura em Matemática da Faal. E-mail limatesco@yahoo.com.br

** Doutoranda em Educação Matemática vinculada ao Programa de Pós-Graduação da FE/Unicamp, grupo Prapem. Professora e coordenadora de Matemática da rede particular de Campinas. E-mail juliana.facanali@gmail.com 
matemática que integram grupos colaborativos e investigativos. Ao tratar desses desafios, consideramos as dimensões social, histórica e antropológica da escola, entendida por nós como uma instituição situada no interior de uma sociedade em contínua transformação e que se modifica, ou não, juntamente com esse entorno.

Eliane tem procurado historiar, numa perspectiva etnográfica (BARTON; HAMILTON, 2004), e compreender, buscando aportes no conceito de letramento (STREET, 2004), as práticas de formação contínua de professores presentes no contexto de um grupo colaborativo de estudos em educação matemática. Sua pesquisa tem estabelecido articulações entre esse conceito e as potencialidades das comunidades de aprendizagem/investigação (COCHRAN-SMITH; LYTLE, 1999).

Juliana, por sua vez, tem trabalhado na perspectiva da história oral (GARNICA, 2006), buscando entrelaçar informações acerca dos desafios do fazer docente do professor de matemática, obtidas por meio de questionários e entrevistas, com suas experiências de professora de matemática e integrante de grupos colaborativos e investigativos e seus referenciais teóricos, na forma de transcriações .

O presente artigo aborda diversos desafios que se colocam aos professores, entre os quais: como ser professor numa escola para todos? Como conhecer as diferentes relações que os alunos estabelecem com o conhecimento e utilizá-las na promoção de uma aprendizagem significativa? Como utilizar as tecnologias no ensino para potencializar a aprendizagem? Para além de apresentar os desafios, objetivamos olhar para os seus desdobramentos em termos da elevação das demandas de trabalho do professor no âmbito do seu volume, de sua variedade e do tempo utilizado em sua realização. Tentamos, também, sinalizar a necessidade de reformulação da formação inicial e contínua do professor, tendo em vista que o modelo atual não contempla os conhecimentos, as habilidades e competências necessárias para lidar com a complexidade das questões cotidianas que surgem na contemporaneidade. Assim, apontamos algumas opções na direção de iniciativas mais cooperativas e investigativas de formação. Tratamos, ainda, da falta de reconhecimento da profissão docente quando apontamos a desvalorização dos saberes docentes nas reformas educacionais, planejadas, implantadas e associadas a mecanismos de controle externo que vinculam o resultado obtido pelos alunos em avaliações de larga escala a sanções ou premiações a estudantes, professores e escolas. Essa mesma falta de reconhecimento é abordada quando falamos da falta de condições de trabalho adequadas e da pouca frequência com que se encontram oportunidades e espaços de formação inicial e contínua de qualidade. A baixa atratividade da carreira docente se evidencia no momento em que discutimos a incompatibilidade dos baixos salários com a complexidade, responsabilidade e relevância do trabalho que os professores realizam. 
Não temos a pretensão de esgotar a temática dos desafios, nem mesmo de explorá-los em profundidade. Queremos, sim, levantá-los, problematizá-los e discuti-los. Diante dessa complexa realidade, colocamo-nos como professoras de matemática, de variados níveis de ensino, que, concomitantemente com o trabalho docente, realizam pesquisa acadêmica e que assumem frente à própria prática uma postura investigativa e colaborativa. Tal postura agrega à atividade docente novos desafios que, ao mesmo tempo em que ampliam o potencial e o alcance educativo das aulas, acabam por se constituir em mais um componente na complexidade da profissão docente. Novas demandas de formação surgem quando há interesse de incentivar tais posturas para que possam estar cada vez mais presentes no interior das salas de aula e extravasar tais espaços, incorporando-se aos alunos-cidadãos e impactando, dessa forma, a sociedade.

\section{Desafios da docência: o contexto da escola e da sala de aula}

Assim como todos os setores da sociedade, a sala de aula vem mudando. No entanto, enquanto a sociedade se transforma numa velocidade vertiginosa, a escola caminha a passos lentos. Uma explicação para esse fato é que, "dado que o mundo é velho, sempre mais do que as nossas próprias crianças, a aprendizagem volta-se inevitavelmente para o passado, não importa quanto a vida seja transcorrida no presente" (ARENDT, 1972, p. 246).

Tem sido difícil, para nós professores, lidar com tais mudanças. Estamos em crise: escola, universidade e professores. Abrimos as portas para todos os alunos, democratizando, teoricamente, o conhecimento, mas não abrimos mão de um ensino elitizado, impermeável à diversidade de alunos que agora frequentam o ambiente escolar em seus diversos níveis.

A escola e a sociedade evoluem de forma entrelaçada ao longo da história, pois "cada progresso tecnológico é acompanhado da necessidade de ser transmitido, através do ensino, às gerações futuras. A Mesopotâmia tinha inventado a escola para as elites, a sociedade industrial inventa a escolarização e o consumo de massa" (DE MASI, 2000, p. 43). E a sociedade da informação, o que inventa? A "escola para todos", agora amparada pela lei. No entanto, essa escola precisa fazer crítica à sociedade da qual faz parte. Precisa, segundo Hargreaves (2001), ensinar para ela, para além dela e apesar dela. Ressaltamos a importância de que nessa escola haja espaço para uma visão antropológica, de acordo com a qual ela se constitui numa das maneiras de os jovens poderem "ingressar em um mundo humano, habitar esse mundo, nele desenvolver competências e encontrar referências, construir relações 
com os outros, construir-se a si próprios como sujeitos humanos e se fazer reconhecer como tais" (CHARLOT, 2001, p. 147).

Ainda na tentativa de entender a escola que se funda nas bases da sociedade da informação, recorremos a Gadotti, que discute o mesmo assunto:

O que cabe à escola na sociedade informacional? Cabe a ela organizar um movimento global de renovação cultural, aproveitando-se de toda essa riqueza de informações. [...]. A escola está desafiada a mudar a lógica da construção do conhecimento, pois a aprendizagem agora ocupa toda a nossa vida. E porque passamos todo o tempo de nossas vidas na escola - não só nós, professores - devemos ser felizes nela. A felicidade na escola não é uma questão de opção metodológica ou ideológica, mas sim uma obrigação essencial dela (GADOTTI, 2000, p. 8).

Falar da felicidade como uma obrigação da escola requer uma mudança de paradigma sobre o que seja o conhecimento e como este é produzido. De acordo com Powell e Bairral (2006, p. 48-49), o conhecimento não se situa apenas no nível da experiência, mas também no nível da reflexão sobre a experiência e sobre os sentimentos acerca dessas experiências. Então, o aprender e o ensinar com os quais estão envolvidos professores e alunos, para que sejam mais amplamente entendidos, precisam compreender uma variável a mais: a afetividade. Isso também se coloca aos professores como um desafio.

A estrutura escolar encontra-se pressionada por forças que agem em sentidos divergentes: o novo modelo de sociedade na qual está inserida e para a qual deve "preparar" seus alunos, as crenças e concepções historicamente construídas sobre seu papel, assim como muitas outras. Talvez por isso a estrutura escolar mova-se tão lentamente pelos trilhos da história. A escola assume o papel de resistência, de resguardar o saber, a história, o "como foi", o "como fazíamos sem"”, ao mesmo tempo em que carrega a responsabilidade de construir uma nova sociedade em vez de, simplesmente, submeter-se a ela. Faz-se necessário discutir essas questões no interior dos estabelecimentos de ensino e de aprendizagem, nos diferentes níveis, e envolver nessa discussão seus protagonistas: acadêmicos, professores escolares e alunos, entre outros.

\section{0 aluno, o professor e as tecnologias na sala de aula: como ir além do velho ensino?}

Ao pensarmos na velocidade de transformação da sociedade, um desafio colocado ao professor é o de lidar com uma geração que está imersa numa sociedade movida pelas tecnologias e em uma escola que as subutiliza, delegando a elas o papel de "nova mídia" e mantendo as concepções do "velho ensino". Quando falamos 
em uso das tecnologias, logo aparecem perguntas como: O PowerPoint virou a lousa do professor? Trocou-se o giz pelo mouse? E aquele "escurinho de cinema", logo pela manhã, auxilia ou compromete a aprendizagem? Porém, não é deste uso das tecnologias que estamos falando e não é este que se configura para nós como desafio.

$\mathrm{O}$ trabalho pedagógico que o professor desenvolve com o computador, por exemplo, pode ter perfis diversos. O professor pode "usá-lo como uma máquina transmissora de conhecimentos para o aluno, ou como um auxiliar na construção desses conhecimentos" (CLÁUDIO; CUNHA, 2001, p. 174). Ao optar pelo primeiro perfil, o professor fará do computar um virador de páginas eletrônico. No entanto, o uso que desafia o professor não é esse e sim aquele em que as tecnologias são utilizadas para instigar o aluno a estabelecer uma relação significativa com o saber. Este uso tem ficado por conta de professores com iniciativa, postura investigava e conhecimentos prévios de tecnologias e que, com sua carga horária já abarrotada, se dispõem, voluntariamente, a estudar para utilizar tais tecnologias de forma a impactar positivamente a educação.

Ambientes computacionais com potencialidades educativas, a exemplo do Winplot, Geogebra, Excel, CMapTools, Prezi, bem como a boa e velha calculadora, se explorados de forma a envolver o aluno no processo de aprendizagem, podem colaborar para que ele venha a ser protagonista desse processo. O uso da tecnologia pode extrapolar o papel de facilitador da vida do aluno e ampliar suas possibilidades de aprendizagem, propiciando interações que "o lápis e o papel" e "a lousa e o giz" não permitiriam. Um exemplo é o uso de um software gratuito como o Winplot, que pode ajudar o aluno a investigar o comportamento de funções, a levantar e testar conjeturas, argumentar, produzir relatórios e apresentar suas descobertas em plenária.

A dimensão desse desafio amplia-se se refletirmos sobre as exigências curriculares impostas ao ensino de matemática, em especial. Os professores perguntam-se: como trabalhar dessa forma com o currículo que temos? O currículo nos amarra, mas, ao mesmo tempo, nos lembra dos conhecimentos que foram importantes ao longo da história do ser humano. A tecnologia é uma demanda do agora, e precisamos equilibrar essas duas faces, promovendo interação entre o histórico e o novo. Esse trabalho precisa ser reconhecido e valorizado.

\section{Relação do aluno com o conhecimento}

Todo e qualquer aluno estabelece alguma relação com o conhecimento. Afirmar que o estudante, principalmente das classes populares, com dificuldades escolares ou com necessidades educacionais especiais não aprende porque não estabelece 
relação com o conhecimento não nos parece correto. Esse aluno, muitas vezes, não estabelece com o conhecimento a relação que esperamos, e nosso papel de professores é de tentar conhecer a natureza dessa relação. Esse é um dos desafios que se colocam ao professor e que, dificilmente, conseguirá enfrentar refletindo sozinho, nos limites de sua própria sala de aula, ou, até mesmo, da escola em que atua.

Relacionar-se com o conhecimento supõe, em parte, aprender. Mas, afinal, o que é aprender? Aprender não tem o mesmo significado para pessoas diferentes, em tempos, espaços e culturas diversas. É preciso saber o que significa aprender para os alunos com os quais trabalhamos, (re)conhecer os conhecimentos que eles consideram relevantes e entender como constroem esse critério de relevância. Isso não significa que devamos nos render a um ensino utilitarista ou aos desejos do aluno, e sim estabelecer uma ponte para ampliar sua bagagem cultural, seus saberes, conhecimentos e sua linguagem, ampliando suas possibilidades de escolha para além de repetir o que vivencia em seu grupo cultural, econômico ou social. Assim, soma-se ao desafio de compreender a natureza da relação que o aluno estabelece com o conhecimento, o desafio de entender como cada um aprende.

O conhecimento escolar, muitas vezes, contraria o conhecimento presente na cultura em que o aluno está inserido, despertando sentimentos contraditórios que o levam a assumir posturas de desinteresse, rebeldia, negação e dificuldade. $O$ conhecimento escolar entra em conflito com a realidade com a qual convive, a linguagem que utiliza e as estratégias de aprendizagem que usa no cotidiano, pois se tratam de práticas sociais diferentes. O papel da escola é fazê-las dialogar entre si, sendo esse mais um desafio com o qual o professor lida, embora não seja exclusivamente seu.

Se antes o fracasso escolar era atribuído ao aluno, pois aquele que não se adequava aos padrões escolares era reprovado, agora esse ônus mudou de mãos, e toda questão referente à aprendizagem do discente tornou-se responsabilidade do professor. A progressão continuada contribuiu para que o aluno deixasse de estudar por "obrigação" e transferiu para o professor a "obrigação" de garantir que todos aprendam. Acreditamos que não é insistindo nessa dicotomia que esse desafio será enfrentado, e sim promovendo a construção de uma relação de corresponsabilidade entre professor e aluno no movimento de ensino e aprendizagem.

Como afirmou Charlot, em entrevista publicada na revista Educação e Pesqui$s a$, "só aprende quem estuda, quem tem uma atividade intelectual. Mas só faço um esforço intelectual se a atividade tem sentido para mim e me traz uma forma de prazer" (REGO; BRUNO, 2010, p. 151).

Questiona-se, certamente, o professor: como fazer para que isso ocorra? Uma posição que nos parece coerente é a de considerar o professor e o aluno como prota- 
gonistas do ensino e da aprendizagem, e não como meros reprodutores. No entanto, as políticas públicas de formação ainda reforçam a utilização de materiais prontos com conteúdos pré-estabelecidos, e muitos alunos não se veem atraídos por essa forma de organizar o conhecimento, estabelecendo com ele relações não significativas do ponto de vista da efetiva aprendizagem. E o desafio de fazer com que essa realidade mude continua sendo do professor!

\section{Possibilidades da postura colaborativa e investigativa}

Não há uma receita pronta para que essa coconstrução ocorra. Nossos trabalhos de pesquisa têm indicado que esses - e outros - desafios têm sido enfrentados de forma mais competente por professores inseridos em contextos colaborativos, nos quais os entraves enfrentados na sala de aula são tomados como ponto de partida para investigações que podem colaborar para a aprendizagem significativa do docente. Tal tática ${ }^{2}$ de enfrentamento pode vir, igualmente, a colaborar para que os professores, para além de assumir sua parcela de responsabilidade nesse processo, encontrem formas de auxiliar, também, o aluno a desempenhar o seu papel no processo de ensino e aprendizagem. Como integrantes do Grupo de Sábado (GdS) ${ }^{3}$ (Juliana desde a fundação, em 1999, e Eliane desde 2003), podemos afirmar que esse espaço viabilizou o diálogo integrado entre teoria e prática e sua ressignificação na forma de saberes docentes e de produção de conhecimento.

$\mathrm{Na}$ contrapartida de políticas públicas de formação continuada, no grupo colaborativo, o professor assume o papel de produtor de conhecimento que resulta de práticas colaborativas e reflexivas de formação. Essas práticas têm como ponto de partida e chegada a sala de aula, e nesse novo papel o professor se sente mais reconhecido e valorizado na especificidade de seus saberes e na complexidade do seu fazer. Esses grupos são entendidos por Fiorentini como um espaço

[...] onde todos os participantes, professores da escola e formadores de professores aprendem uns dos outros. Todos se constituem, no grupo, em aprendizes e "ensinantes". Os acadêmicos aprendem com os professores escolares os saberes experienciais que estes produzem no contexto complexo e adverso da prática escolar, re-significando, assim, seus saberes profissionais enquanto formadores de professores. Os professores, face aos seus desafios e problemas, com a ajuda dos acadêmicos, produzem, como verificou Jiménez (2002), re-significações sobre o que sabem e fazem (FIORENTINI, 2004, p. 60).

Professores que participam de grupos colaborativos e que desenvolvem posturas colaborativas e investigativas frente à própria prática produzem e compartilham saberes com seus pares, ampliando, colaborativamente, seu rol de táticas para lidar com tais desafios. 
No GdS, esse movimento nasceu do trabalho com as investigações matemáticas (ABRANTES; LEAL; PONTE, 1996) e procurou aliar os desafios que emergiam do fazer dos professores, a prática colaborativa entre pares e a reflexão acerca dessa prática, utilizando referenciais teóricos. Esse trabalho iniciado com o estudo de tarefas investigativas (PONTE; BROCARDO; OLIVEIRA, 2003) resultou não somente na reformulação de nossas práticas docentes como também num constructo teórico denominado por nós de "tarefas exploratório-investigativas". Passamos a falar em "postura investigativa", que pode ser entendida como um "modo de ser" professor que contempla um movimento constante no sentido de compreender nossas próprias práticas por meio da ação, da reflexão, da colaboração e do diálogo com nossos pares e com a teoria. Esse "modo de ser" professor, exercitado no GdS, tem contribuído para um novo "modo de fazer" o ensino da matemática e de forjar a relação com o conhecimento no que diz respeito tanto aos professores quanto aos alunos.

A postura colaborativa e investigativa é uma competência que nos parece essencial ao professor de hoje. No entanto, tal competência necessita do desenvolvimento de habilidades que podem ser construídas e exercitadas no grupo colaborativo e investigativo. Dessa forma, esse grupo exerce papel de ambiente de formação contínua do professor, visto que, aprendendo a trabalhar de forma colaborativa e investigativa, poderá, também, colaborar no sentido de transformar práticas escolares e ajudar alunos a estabelecerem relações significativas com o saber e tornarem-se protagonistas de sua própria aprendizagem.

Duas pesquisadoras norte-americanas têm sido, para nós, referencial teórico na busca de uma melhor compreensão do papel dos grupos colaborativos no enfrentamento dos desafios encontrados por professores. Segundo Cochran-Smith e Lytle,

O aprendizado por meio da participação em investigações sistemáticas e intencionais sobre a prática [...] cria a colaboração, reconsiderando o que antes era dado, desafiando as estruturas da escola e da sala de aula, ao deliberar sobre o que significa saber e o que é considerado conhecimento perito, repensando categorias educacionais, construindo e reconstruindo enfoques de interpretação, e tentando desvelar os valores e interesses servidos pelos arranjos do sistema escolar. Quando o trabalho em comunidades se baseia no conhecimento $d a$ prática - seja o trabalho referente à pesquisa do professor, pesquisa-ação ou investigação dos praticantes (practioneers) - o objetivo não é a pesquisa nem a produção de "descobertas", como é geralmente o caso das pesquisas de universidades. Ao contrário, o objetivo é a compreensão, a articulação, e ao final a transformação das práticas e das relações sociais de forma a trazer mudanças fundamentais nas salas de aula, escolas, distritos, programas e organizações profissionais. Na base deste compromisso se encontra uma responsabilidade profunda e apaixonada em relação ao aprendizado dos estudantes, de suas chances na vida, e em relação a uma transformação das políticas e estruturas que limitam o acesso dos estudantes a estas oportunidades (1999, p. 279). 
O grupo é, para nós, um laboratório de criação, de experimentação e de análise dos resultados de tudo o que levamos para nossas salas de aula. Esse movimento é o que nos torna pesquisadoras de nossas práticas. Para mudar perspectivas e concepções de ensino, promover realmente mudanças, não basta treinar professores como preferem as pedagogias tecnicistas e as políticas neoliberais. $\mathrm{O}$ grupo pode ser entendido como uma comunidade de investigação e aprendizagem na qual o foco é o ensino de matemática. As diferenças de olhar sobre esse ensino, devido aos diversos níveis e lugares nos quais cada participante atua, permitem uma riqueza de experiências que, ao serem compartilhadas, provocam o que Bakhtin chama de excedente de visão:

O excedente de minha visão sobre o outro contém, em germe, a forma acabada do outro, cujo desabrochar requer que eu lhe complete o horizonte sem tirar a originalidade. Devo identificar-me com o outro e ver o mundo através de seu sistema de valores, tal como ele vê; devo colocar-me em seu lugar, e depois, de volta ao meu lugar, contemplar seu horizonte com tudo o que se descobre do lugar que ocupo fora dele (2000, p. 40).

Esse "outro", por ser diferente, permite que eu reflita mais sobre meu fazer ao compartilhar com ele esse fazer. O próprio ato de compartilhar torna-se uma tarefa reflexiva, pois é preciso pensar como dizer sobre o que fazemos e depois interpretar o que o outro está entendendo sobre o que dizemos. Nesse compartilhamento, todos aprendem com todos!

\section{Limites da postura colaborativa e investigativa: além da sala de aula}

Embora apontemos os grupos colaborativos como espaços privilegiados de formação docente, na perspectiva do professor que entende a postura investigativa e colaborativa como tática útil no enfrentamento dos desafios que povoam o complexo cotidiano escolar, reconhecemos que os grupos colaborativos e investigativos ainda não lhe permitem o enfrentamento de desafios mais amplos, que envolvam contextos macros, extrapolando os limites da sala de aula e da escola. A seguir, abordaremos esses desafios.

\section{Acúmulo de trabalho}

A sociedade informacional levou a escola a incorporar novas atribuições ao professor em termos de trabalho burocrático e pedagógico. Saber explorar as potencialidades pedagógicas de mídias como TV, Facebook, Twiter, Google, Wikipédia, Youtube e outras fontes é uma demanda em crescimento. A utilização de notebook, 
netbook, iPad, celulares, calculadoras, sistemas informatizados das escolas, atendimento online também figura como nova demanda para o professor.

O uso dessas tecnologias, porém, acaba, muitas vezes, se transformando em trabalho não remunerado para o professor. Sobre esse profissional recai a responsabilidade de abastecer a agenda online dos alunos, explicar para eles que Google não é fonte, indicar-lhes fontes confiáveis, lançar notas no sistema (e como esse sistema falha, também lançá-las na forma tradicional), disponibilizar material para a classe no portal virtual e atender solicitações da secretaria da escola via e-mail fora do horário de trabalho. É preciso repensar tais situações.

Essas novas demandas geram acúmulo de tarefas e afetam desde o professor da escola básica, que atua em escolas públicas ou particulares, até o professor pesquisador da universidade. O docente precisa se desdobrar, lecionando em várias escolas e períodos e, mesmo assim, muitas vezes, não recebe uma remuneração adequada a sua formação e a sua importância na sociedade. Em algumas escolas particulares, a remuneração é mais apropriada, mas as exigências decorrentes do excesso de burocracias, do trabalho gerado pelas tecnologias, do atendimento de pais que consideram a escola uma prestadora de serviços educacionais acarretam outros problemas não menos graves.

No ensino superior, muitos desses problemas se repetem, e, especialmente na esfera pública, há, ainda, a exigência de cumprimento de índices pautados em produtividade. Apesar do mal-estar, pouco se consegue fazer contra os mecanismos que exigem essa produtividade. Segundo Machado e Bianchetti, “o trabalhador-pesquisador reclama fazer mais do que quer ou pode. Critica, porém acata. Análises sobre produtivismo acadêmico responsabilizam, não sem razão, organismos internacionais e nacionais e o sistema vigente. Observam-se, no entanto, mudanças escassas e resignação" (2011, p. 244).

\section{Reformas educacionais}

Reformas educacionais têm sido propostas, a "toque de caixa", sem participação dos professores, como no caso da proposta curricular do estado de São Paulo, implementada em 2008. A academia, ou quem a representa nos órgãos governamentais responsáveis, não tem tempo, espaço ou interesse de discutir com o professor as bases de uma verdadeira mudança curricular.

Além de propostas elaboradas por especialistas, os professores precisam, ainda, conviver com uma política salarial de bônus, pautada em resultados de avaliações externas. Tal política foi trazida para o Brasil sem que se considerassem estudos como os de Ravitch (2010), autora que foi peça-chave durante o processo 
de implementação dessa política nos Estados Unidos e, agora arrependida, aponta críticas a todo o sistema criado por meio de fortes argumentos sobre sua ineficácia. Apesar disso, o Brasil parece importar essa mesma política sem medir suas consequências. Na citação abaixo, a autora resume, em poucas palavras, uma conclusão básica que deveria ser objeto de estudos de qualquer implementador de políticas públicas da educação.

Existe um número limitado de horas e minutos no dia escolar, e se mais tempo é devotado a testagem e preparação para testes, então menos tempo estará disponível para ensinar matérias que não estarão nos testes estaduais. A falta de atenção à história, ciências e artes diminui a qualidade de vida das crianças, a qualidade de vida diária na escola e até mesmo a performance nos testes (RAVITCH, 2010, p. 149)

Para o aluno ter sucesso nas avaliações externas de larga escala, o que se prega é a necessidade de desenvolver nele competências e habilidades. No entanto, o que muitas vezes se vê é o treinamento para tais avaliações e com grande enfoque no aluno "mediano" com possibilidades de atingir os objetivos mínimos essenciais nas avaliações em larga escala, para que a escola e o professor não sofram com ausência de bônus ou corte de verbas. Porém, essas formas de atuação que, em muitos casos, acontecem estão em desacordo com perspectivas críticas de formação para a transformação da sociedade. O professor, então, se vê sob a pressão da sociedade para formar cidadãos capazes de transformá-la, ao mesmo tempo em que seu desempenho é julgado pelos índices alcançados por seus alunos nessas avaliações externas.

De todas as atividades que constituem ou aspiram ser profissões, somente a docência tem a tarefa formidável de criar as habilidades e capacidades humanas que capacitarão a sociedade a sobreviver e ser bem-sucedida na era da informação. Até mesmo e, especialmente em países menos desenvolvidos, espera-se que os professores, mais que qualquer outro grupo profissional, construam comunidades de aprendizagens, criem a sociedade do conhecimento e desenvolvam as capacidades para inovação, flexibilidade e compromisso de mudança, que são essenciais para prosperidade econômica no século XXI (HARGREAVES, 2001, p. 1).

Mais desafios se colocam ao professor, que convive com eternos dilemas: como equilibrar-se entre o que a escola quer que se ensine para obter bons resultados nas avaliações externas, o que aprendeu com os especialistas que se deve ensinar, o que acredita que o aluno precisa realmente saber e o que o aluno quer aprender agora? É possível ensinar tudo, de forma significativa para todos? Não temos respostas a essas perguntas, mas podemos trazer, apenas a título de curiosidade, algumas das muitas lições que Ravith aponta em seu livro. 
Os fundamentos de uma boa educação serão encontrados na sala de aula, em casa, na comunidade e na cultura, mas os reformadores continuam a procurar por atalhos e respostas rápidas. [...]. As nossas escolas não irão melhorar se os políticos que nos governam se meterem no território pedagógico e tomarem decisões que deveriam ser feitas por educadores profissionais. [...]. As nossas escolas não irão melhorar se nós valorizarmos apenas o que os testes mensuram. [...]. As nossas escolas não irão melhorar se confiarmos exclusivamente nos testes como meio de decidir o destino de estudantes, professores, diretores e escolas. [...]. As nossas escolas não irão melhorar se nós as entregamos aos poderes mágicos do mercado (2010, p. 251-253).

\section{Atratividade da carreira}

Todos os fatores até aqui expostos têm desestimulado jovens a seguir a profissão docente, gerando um círculo vicioso que afeta ainda mais a qualidade do ensino. Atualmente, os licenciandos que se tornam professores nas escolas públicas são aqueles que, incentivados por projetos como Prouni, Fies, Escola da Família, buscam nas faculdades particulares uma profissão. Estas, em muitos casos, oferecem cursos "aligeirados" que não resolvem seu problema de falta de bagagem, principalmente no que diz respeito às licenciaturas em Matemática, e raramente problematizam as questões sociais da escola pública. Por seu turno, os licenciandos das faculdades públicas desistem do ensino público assim que esbarram em sua realidade, conforme afirmou a pesquisadora Marli André, em palestra proferida no $17^{\circ}$ Cole em 2009, baseada em resultados de suas próprias pesquisas (HOBOLD; ANDRÉ, 2009).

\section{Políticas de formação do professor: inicial e continuada}

Segundo Gatti e Barreto (2009, p. 20), devido aos problemas crescentes nos cursos de formação inicial de professores, a ideia de formação continuada como aprimoramento profissional foi se deslocando, também, para uma concepção de formação compensatória destinada a preencher lacunas da formação inicial.

Cursos de formação continuada têm sido propostos, porém com ideias baseadas na racionalidade técnica ${ }^{4}$, o que, comprovadamente, não tem resolvido o problema. Tais cursos acontecem em tempos e espaços descontínuos e não abrem espaço para trocas, para o retorno daquilo que aprendemos e levamos para a sala de aula. Não há o "depois", ou seja, novos encontros para buscar soluções para as dificuldades encontradas, o que, muitas vezes, gera o abandono de novas práticas e posturas pedagógicas disseminadas pelas capacitações.

Por meio desses cursos, as secretarias de educação podem cumprir o papel de difundir suas propostas de ensino, e, em alguns casos, novas ideias e resultados de 
pesquisas voltadas para o ensino de todas as disciplinas do ensino, em especial da matemática. Concordamos que, para esse fim, as capacitações podem ser consideradas um caminho, pois é difícil atingir um grande número de professores por meio de grupos de estudo. Cabe, entretanto, o seguinte questionamento: essa modalidade de formação (des)continuada tem dado conta das transformações necessárias à prática de sala de aula para que tenhamos uma educação de qualidade?

Essa descontinuidade está presente, também, dentro das próprias escolas, especialmente as públicas, onde gestores são substituídos constantemente e professores seguem, igualmente, um padrão de rotatividade, orquestrado pela falta de atratividade na carreira e pela desvalorização de quem nela tenta permanecer. $\mathrm{O}$ Horário de Trabalho Pedagógico Coletivo (HTPC) tornou-se um espaço burocrático, no qual os professores recebem recados ou tentam dar conta das novas demandas já apresentadas, preenchem fichas de avaliação, participam de cursos online, muitas vezes distantes de sua necessidades, oferecidos pelas secretarias de educação de forma não presencial com a intenção de atingir mais pessoas e baratear os custos.

\section{Desafios do professor-pesquisador}

Ao analisarmos programas institucionais de bolsa de estudo para professores, fica muito claro que há uma falta de interesse na existência do professor-pesquisador que atua, realmente, no ensino básico. No caso de São Paulo, por exemplo, o professor da escola pública tem incentivos como o projeto Bolsa Mestrado/Doutorado, desde que a pesquisa esteja voltada, necessariamente, para a sua sala de aula. Esse professor não pode discutir problemas mais amplos ou que o levem a se tornar, também, um formador de professores. Parece não haver interesse político em agregar valores ao próprio quadro de servidores, fazendo deles pesquisadores que atuarão em benefício do sistema de ensino como um todo. Há uma elite de especialistas, politicamente escolhidos, que cumprem essa função, mantendo o professor em seu devido lugar de reprodutor.

Em contrapartida, se queremos ser pesquisadores mais livres, temos, também, incentivos de bolsas como da Fapesp e da Capes, mas a primeira sequer aceita que o professor trabalhe, e a segunda libera até oito horas de trabalho semanal, desde que esteja relacionado com a pesquisa. Ora, essa teria tudo para ser uma ótima oportunidade para o professor-pesquisador, mas, se ele é professor efetivo, a carga horária semanal mínima que pode assumir é de dez aulas, fato que se configura em impedimento. Concluímos, então, que a pesquisa do professor, quando ocorre, encontra dificuldades de ultrapassar as paredes da sala de aula e que não 
há interesse em uma aproximação real entre a pesquisa acadêmica e o ensino no nível básico, a partir da perspectiva do professor.

\section{Considerações finais}

Para nós autoras, os papéis de professor e de pesquisador relacionam-se de forma integrada. A postura investigativa deve estar presente no interior das salas de aula, instigando o aluno a estabelecer com o conhecimento uma relação da mesma natureza. Acreditamos que, como pesquisadores, os professores precisam cuidar para não se perderem nos labirintos teóricos, que, muitas vezes, distanciam a pesquisa acadêmica da realidade de sala de aula, desenvolver trabalhos teóricos que tenham sentido e significado no cotidiano da prática docente. Em contrapartida, os pesquisadores, no papel de professores, precisam desenvolver práticas de ensino e aprendizagem ancoradas não somente em pressupostos teóricos, como também em saberes docentes.

Gatti e Barreto (2009) apontam que um caminho possível e necessário é a institucionalização do desenvolvimento profissional do professor, em termos de uma política nacional de formação continuada e definem vários pontos a serem repensados para termos uma política eficiente nesse sentido: articulação entre formação inicial e formação continuada, introdução de estágios de formação continuada, prioridade do vínculo com a realidade das escolas, articulação entre processos de avaliação e formação continuada, formação dos formadores de docentes, dimensão psicossocial da formação continuada, acesso a bens culturais, mecanismos de incentivo ao desenvolvimento profissional, investimento em investigação, articulação entre políticas e sua continuidade.

Enquanto essas condições não ultrapassam o nível de propostas, vamos construindo, colaborativamente, nos espaços que conseguimos conquistar, nossa postura investigativa. Estar em grupos, pensando colaborativamente, tem incentivado professores a criar outros espaços colaborativos. Isso é o que nos permite acreditar na possibilidade de lutar, também, contra esses desafios com base numa rede de grupos colaborativos que, aos poucos, e à revelia das políticas públicas, está sendo formada.

Segundo Cochran-Smith e Lytle,

[...] os professores, ao longo de sua vida, têm papel central e crítico na geração de conhecimento sobre a prática, uma vez que suas salas de aula são locais de investigação, e, ao conectar seu trabalho nas escolas a questões mais amplas, assumem um ponto de vista crítico da teoria e pesquisa de outros. Redes de professores, comunidades de investigação e demais coletivos escolares nos quais os professores e outros somam esforços para construir conhecimento são o contexto privilegiado para o aprendizado do professor (1999, p. 273, grifo nosso). 
Concordamos com as autoras, ao compreendermos a escola como espaço de construção e em construção. Como participantes desse espaço, percebemos que estão ocorrendo mudanças em seu interior e, consequentemente, nas salas de aula. É preciso dar a conhecer tais mudanças, conferindo-lhes visibilidade e valor, para que se tornem catalisadoras de transformações mais abrangentes que possam vir a promover o caminhar da educação. Enquanto as ignorarmos e trabalharmos solitariamente, ou em grupos fechados, apenas envolvidos em projetos de autoria própria ou impostos/propostos, grandes transformações deixarão de ocorrer.

\section{Possibilities and limits of collaborative and investigative attitude of mathematic's teacher as tactics to fight the complexity of teaching}

\section{Abstract}

This article was written to support the Panel presented at the 4th National Meeting of Mathematics Education and 17TH Mathematics Education Regional Day, which had as its theme "Complexity of contemporary classroom". As researchers the complexity of teaching and training of teachers in collaborative contexts, we present and discuss some of the challenges faced daily by teachers who teach mathematics, as well as possible tactics (DE CERTEAU, 1994) to your face. We describe some of these challenges, permeating theoretical references on the issues with reflections from our teaching experiences and collaborative groups and investigative members. We point out the investigative stance and support of collaborative groups (FIORENTINI, 2004) or research/learning communities (COCHRAN-SMITH; LYTLE, 1999) as possible ways to assist teachers in coping with these challenges. However, we recognize that these alternatives have limitations especially when the challenges presented to teachers exceed the boundaries of the classroom.

Keywords: Collaboration. Investigative attitude. Math. Possibilities and limits. Teacher.

\section{Notas}

1 A escola é o espaço de significar, por exemplo, o aprendizado de cálculos empregando formas alternativas à utilização da calculadora, como o uso de algoritmos e do cálculo mental. A significação dos algoritmos pode ser feita de maneiras variadas e complementares. Um caminho possível é o de discutir o lento e complexo processo, situado historicamente, de migração do sistema romano para o indo-arábico, que facilitava tanto a representação dos números como a realização dos cálculos. Tal discussão pode facilitar a compreensão do conceito de valor posicional e da base decimal enquanto desenvolvimento intelectual que propiciou desenvolvimento tecnológico.

2 O conceito de tática é entendido por nós no sentido atribuído por De Certeau (1994). Porém, para entendê-lo melhor, julgamos importante sua contraposição com o conceito de estratégia do autor: "Chamo de 'estratégia' o cálculo das relações de forças que se torna possível a partir do momento em que um sujeito de querer e poder é isolável de um 'ambiente'. Ela postula um lugar capaz de ser circunscrito como um próprio e portanto capaz de servir de base a uma gestão de suas relações com uma exterioridade extinta. A nacionalidade política, econômica ou científica foi construída segundo esse modelo estratégico [...]. Denomino, ao contrário, 'tática' um cálculo que não pode contar com um próprio, nem, portanto, com uma fronteira 
que distingue o outro como totalidade visível. A tática só tem por lugar o outro. Ela aí se insinua, fragmentariamente, sem apreendê-lo por inteiro, sem poder retê-lo à distância. Ela não dispõe de base onde capitalizar e assegurar uma independência em face das circunstâncias. O 'próprio' é uma vitória do lugar sobre o tempo. Ao contrário, pelo fato de seu não lugar, a tática depende do tempo, vigiando para 'captar no voo' possibilidade de ganho" (DE CERTEAU, 1994, p. 47, grifo nosso).

3 Maiores informações sobre o grupo podem ser obtidas em: http:/grupodesabado.webnode.com/.

4 "A racionalidade técnica, a epistemologia da prática predominante nas faculdades, ameaça a competência profissional, na forma de aplicação do conhecimento privilegiado a problemas instrumentais da prática. O currículo normativo das escolas e a separação entre a pesquisa e a prática não deixam espaço para a "reflexão-na-ação", criando, assim, um dilema entre o rigor e a relevância para escudares, profissionais e estudantes" (SCHÖN, 2000, prefácio).

\section{Referências}

ABRANTES, P.; LEAL, L. C.; PONTE, J. P. Investigar para aprender. Lisboa: APM, 1996.

ARENDT, H. A crise na educação: entre o passado e o futuro. São Paulo: Perspectiva, 1972. p. 221-247. (Between Past and Future): 1961.

BAKHTIN, M. Estética da criação verbal. São Paulo: Martins Fontes, 2000.

BARTON, D.; HAMILTON, M. La literacidad entendida como práctica social. Tradução [1998] in: ZAVALA, V.; NIÑO-MURCIA, M.; AMES, P. (Ed.). Escritura y sociedad: nuevas perspectivas teóricas y etnográficas. Lima: Red para El Desarrollo de las Ciencias Sociales en el Perú, 2004.

CHARLOT, B. (Org.). Os jovens e o saber: perspectivas mundiais. Porto Alegre: Artmed, 2001.

CLÁUDIO, D. M.; CUNHA, M. L. As novas tecnologias na formação de professores de matemática. In: CURY, H. N. (Org.). Formação de professores de matemática: uma visão multifacetada. Porto Alegre: Edipucrs, 2001.

COCHRAN-SMITH, M.; LYTLE, S. L. Relationships of knowledge and practice: teacher learning in communities. Review of Research in Education, USA, v. 24, p. 249-305. 1999. Trad. de Grupo de Estudo e Pesquisa sobre Formação de Professores de Matemática (GEPFPM/FE/Unicamp).

DE CERTEAU, M. A invenção do cotidiano: artes de fazer. Rio de Janeiro: Vozes, 1994.

DE MASI, D. O ócio criativo. Rio de Janeiro: Sextante, 2000.

FIORENTINI, D. Pesquisar práticas colaborativas ou pesquisar colaborativamente? In: BORBA, M.C.; ARAÚJO, J. L. (Org.). Pesquisa qualitativa em educação matemática. Belo Horizonte: Autêntica, 2004.

GARNICA, A. V. M. História oral e educação matemática: um inventário. Revista Pesquisa Qualitativa, São Paulo: SE\&PQ, ano 2, n. 1, p. 137-160, 2006.

GADOTTI, M. Perspectivas atuais da educação. São Paulo em Perspectiva, v. 14, n. 2, 2000.

GATTI, B. A.; BARRETO, E. S. S. Professores do Brasil: impasses e desafios. Brasília: UNESCO, 2009.

HARGREAVES, A. Teaching as a paradoxical profession. ICET - $46^{\text {th }}$ World Assembly: Teacher Education (CD-ROM), Santiago - Chile, 2001, 22p.

HOBOLD, M. S.; ANDRE, M. E. D. A. As representações de estudantes de licenciatura sobre a profissão docente. Revista UNIVILLE, v. 14, p. 07-17, 2009.

MACHADO, A. M. N.; BIANCHETTI, L. (Des)fetichização do produtivismo acadêmico: desafios para o trabalhador-pesquisador. $R A E$, São Paulo, v. 51, n. 3, maio/jun., p. 244-254, 2011. 
PONTE, J. P.; BROCARDO, J.; OLIVEIRA, H. Investigações matemáticas na sala de aula. Belo Horizonte: Autêntica, 2003.

POWELL, A.; BAIRRAL, M. A escrita e o pensamento matemático: interações e potencialidades. Campinas, SP: Papirus, 2006.

RAVITCH, D. The death and life of the great american school system: how testing and choice are undermining education. New York: Basic Books, 2010.

REGO, T. C.; BRUNO, L. E. N. B. Desafios da educação na contemporaneidade: reflexões de um pesquisador - entrevista com Bernard Charlot. Educação e Pesquisa, São Paulo, v. 36, n. especial, p. 147-161, 2010.

SCHÖN, D. Educando o profissional reflexivo: um novo design para o ensino e a aprendizagem. Porto Alegre: Artes Médicas Sul, 2000.

STREET, B. Los nuevos estudios de literacidad. In: ZAVALA, V.; NIÑO-MURCIA, M.; AMES, P. (Ed.). Escritura y sociedad: nuevas perspectivas teóricas y etnográficas. Lima: Red para El Desarrollo de las Ciencias Sociales en el Perú, 2004 [1993], p. 81-107. 